\title{
PEMANFAATAN LIMBAH KOTORAN SAPI MENJADI PUPUK ORGANIK DALAM UPAYA PENINGKATAN PEREKONOMIAN GAPOKTAN DESA SAMBIREMBE
}

\author{
${ }^{1)}$ Sri Hilmi Pujihartati, ${ }^{2)}$ Roby Delji, ${ }^{3)}$ Raka Nenggala Sukma, ${ }^{4}$ Shifa Parama Dita Adzani \\ ${ }^{1)}$ Program Studi Sosiologi, Fakultas Ilmu Sosial dan Politik, Universitas Sebelas Maret \\ ${ }^{2,3,4)}$ Fakultas Prtanian, Universitas Sebelas Maret, Surakarta \\ E-mail : srihilmi@staff.uns.ac.id
}

\begin{abstract}
ABSTRAK
Tujuan riset pengabdian ini adalah memberikan pelatihan dan praktik pembuatan pupuk organik dari limbah kotoran sapi kepada Gapoktan Desa Sambirembe, Kecamatan Kalijambe, Kabupaten Sragen. Pengabdian dilakukan sebagai upaya penunjang perekonomian masyarakat, khususnya anggota Gapoktan di masa pandemi Covid-19. Metode pelaksanaan kegiatan tersebut dilakukan dengan melakukan penyuluhan sebagai tahap awal pemahaman kelompok tani terkait pentingnya pengolahan limbah kotoran sapi yang dapat dimanfaatkan sebagai pupuk. Metode pelaksanaan selanjutnya adalah pembuatan pupuk berupa penaburan stardeck dan dolomit beserta proses lanjutan berupa pembalikan. Hingga pupuk sudah siap, dilakukan branding dan pemasaran. Hasil kegiatan pengabdian masyarakat pada penyuluhan, membuat masyarakat memahami pentingnya pengolahan limbah kotoran sapi untuk diolah menjadi pupuk kadang. Pelaksanaan kegiatan tersebut berlanjut pada pelatihan dan praktik pembuatan pupuk. Serangkaian kegiatan pembuatan pupuk organik dilakukan dengan hasil yang sesuai dengan perencanaan dan pencanangan pengabdian masyarakat, yaitu produk pupuk organik siap pakai dan siap jual untuk menunjang perekonomian kelompok tani di masa pandemi.
\end{abstract}

Kata Kunci: community service, cow dung waste, organic fertilizer, farmer groups

\begin{abstract}
The purpose of this community service research is to provide training and practice of making organic fertilizers from cow dung waste to Gapoktan Sambirembe Village, Kalijambe District, Sragen Regency. This service was carried out as an effort to support the community's economy, especially Gapoktan members during the Covid-19 pandemic. The method of implementing these activities is carried out by providing counseling as an initial stage of understanding the farmer groups regarding the importance of processing cow dung which can be used as fertilizer. The next method of implementation is the manufacture offertilizers in the form of stardeck and dolomite sowing along with a further process of reversing. Until the fertilizer is ready, branding and marketing are carried out. The results of community service activities at outreach, made the community understand the importance of processing cow manure to be processed into fertilizer sometimes. The implementation of these activities continues with training and practice of making fertilizer. A series of organic fertilizer production activities were carried out with results in accordance with the planning and declaration of community service, namely ready-to-use and ready-to-sell organic fertilizer products to support the economy of farmer groups during a pandemic.
\end{abstract}

Keyword: isi, format, artikel.

\section{PENDAHULUAN}

Desa Sambirembe merupakan salah satu desa agraris di Kecamatan Kalijambe, Kabupaten Sragen, Jawa Tengah. Kecamatan Kalijambe merupakan bagian dari wilayah administratif Kabupaten Sragen. Kecamatan Kalijambe, berdasarkan data Badan Pusat Statistik, terletak berada di antara batas wilayah dengan Kecamatan Gemolong di sisi utara, Kecamatan Plupuh di sisi timur, Kabupaten Karanganyar di sisi selatan, dan Kabupaten Boyolali di sisi barat (2020) [1]. Wilayah dengan luas 46,95 $\mathrm{km}^{2}$ tersebut terdiri atas 14 desa. Desa atau kelurahan merupakan wilayah administratif di bawah kecamatan yang dipimpin oleh kepala desa. 
Salah satu desa yang berada di Kecamatan Kalijambe adalah Desa Sambirembe. Desa Sambirembe, berdasarkan data Badan Pusat Statistik, memiliki luas lahan 329,61 Ha, dengan perincian 143,00 Ha merupakan lahan sawah dan 186,61 merupakan lahan bukan sawah. Pemanfaatan lahan sawah digunakan sebagai pengembangan komoditas pertanian seperti padi. Pemanfaatan lahan bukan sawah yang terdiri atas lahan pekarangan, tegal/kebun, dan padang/gembala di Desa Sambirembe telah dilakukan secara maksimal dengan pengembangan komoditas jagung, singkong, tebu, cabai, kedelai, pisang, dan lain-lain.

Atas produktifnya sektor pertanian di Desa Sambirembe, maka dibentuklah kelompok tani yang disesuaikan dengan komoditas dan kebayanan masing-masing. Terdapat tiga jenis kelompok, yaitu kelompok petani, kelompok peternak, dan kelompok pekebun. Kelompok petani memiliki potensi yang besar dalam pemanfaatan komoditas yang dihasilkan. Namun, untuk kelompok peternak, potensi yang dilakukan sejauh ini hanyalah mengembangbiakkan sapi sebagai ternak. Pemanfaatan lain atas sapi ternak tersebut belum digagas oleh kelompok peternak. Oleh karena itu, kegiatan pengabdian masyarakat sebagai pelaksanaan dari riset ini adalah mengupayakan pemanfaatan limbah kotoran sapi. Produk pupuk organik, selain mengurangi penggunaan pupuk anorganik (kimia) dalam usaha pertanian, juga dapat bermanfaat untuk menunjang perekonomian kelompok tani, khususnya peternak, apabila dijadikan produk pupuk.

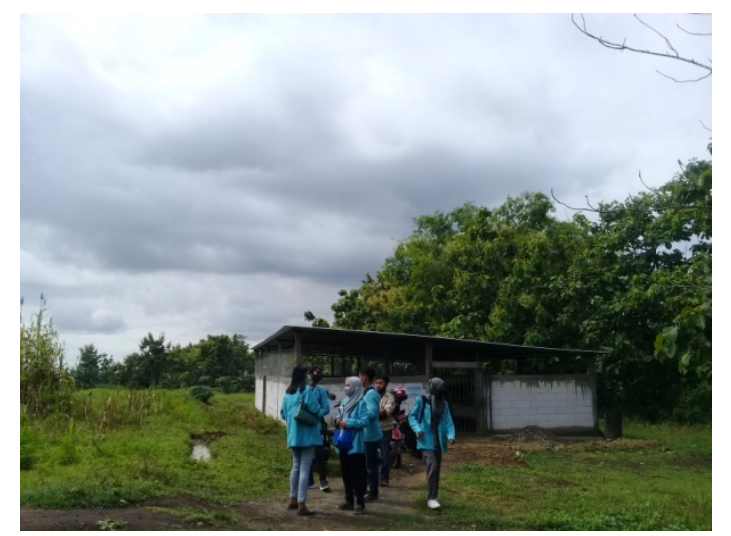

Gambar 1. Area pertanian dan peternakan Desa Sambirembe

Berdasarkan adanya pemerian dalam lampiran Peraturan Menteri Pertanian Republik Indonesia Nomor 67/Permentan/Sm.050/12/2016 tentang Pembinaan Kelembagaan Petani pada bab (i), diketahui bahwa Kelompok Tani merupakan kumpulan petani/peternak/pekebun yang dibentuk oleh petani setempat dengan didasarkan pada kepentingan, kondisi lingkungan sosial, ekonomi, sumber daya, dan komoditas yang sama untuk meningkatkan dan mengembangkan usaha dari setiap anggota. Kelompok tani yang terbentuk tentu memiliki masing-masing potensi yang dapat dikembangkan sebagai upaya pemberdayaan kelompok. Hal tersebut bersambung pada pembentukan Gabungan Kelompok Tani atau yang dapat disebut sebagai Gapoktan. Gapoktan merupakan kumpulan dari kelompok-kelompok tani yang bergabung dan bekerja sama untuk meningkatkan skala perekonomian dan efisiensi usaha dari komoditas yang dikembangkan (Permentan, 2016) [2].

Gapoktan Desa Sambirembe memiliki rumah peternakan yang terletak di Dusun Wonosari. Rumah peternakan tersebut berisikan delapan ekor sapi yang merupakan milik anggota kelompok tani. Kedelapan sapi tersebut merupakan sapi betina yang dihibahkan oleh pemerintah Kabupaten 
Sragen kepada kelompok tani. Oleh karena merupakan program baru, pengelolaan peternakan belum dilakukan secara maksimal, upaya pengolahan limbah kotoran sapi menjadi pupuk organik merupakan langkah yang mutakhir bagi kelompok tani tersebut merupakan progres yang baik untuk kesejahteraan anggota kelompok tani.

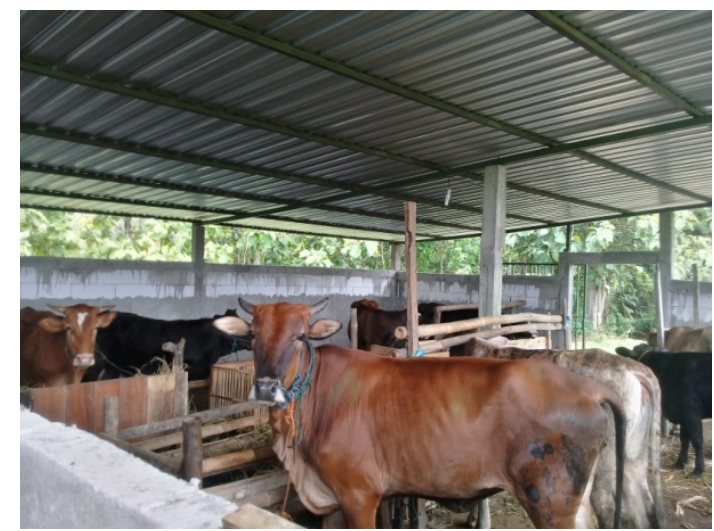

Gambar 2. Rumah peternakan Gapoktan Desa Sambirembe

Pupuk adalah bahan organik maupun anorganik yang mengadung bahan baku pertumbuhan tanaman yang ditambahkan pada media tanam atau tanaman untuk memenuhi kebutuhan zat hara yang diperlukan oleh tanman agar tumbuh dengan optimal dan mampu meningkatkan produksi dengan baik (Setiawan, 2010) [3]. Pupuk yang terdiri atas dua jenis, pupuk organik dan anorganik, masing-masing memiliki kelebihan dan kekurangan. Penggunaan pupuk anorganik memang lebih efektif dan cepat, tetapi dampak jangka panjang berupa kerusakan struktur tanah. Di sisi lain, pupuk kandang bermanfaat untuk memperbaiki struktur tanah, bahkan juga berfungsi sebagai penyedia sumber hara, makro, dan mikro.

Setiawan menjelaskan bahwa terdapat dua jenis pupuk kandang, yaitu pupuk kandang padat dan pupuk kandang cair. Pupuk kandang padat berasal dari limbah kotoran hewan, baik yang telah difermentasi maupun yang belum difermentasi. Sementara itu, pupuk kandang cair berasal dari kotoran hewan yang masih segar dan bercampur dengan urine atau dicairkan dengan air. Hewan penghasil kotoran yang dapat digunakan sebagai pupuk kandang di antaranya adalah sapi, kuda, kerbau, kambing, domba, dan babi. Pupuk kandang yang dapat dihasilkan oleh Gapoktan Desa Sambirembe berasal dari ternak sapi. Pupuk kadang sapi memiliki kandungan serat kasar dan air yang tinggi, oleh karenanya perlu pengompasan dengan cara mencampurkan bahan seperti jerami [3].

Riset pengabdian masyarakat terkait dengan pupuk kandang sudah pernah dilakukan sebelumnya. beberapa riset tersebut di antaranya adalah: (1) Perintisan usaha bersama produksi pupuk organik dengan Poktan Tani Makmur dengan UKM industri alkohol, Sukoharjo oleh Happy Mulyani dkk. (2016) [4]. Riset tersebut menghasilkan tumbuhnya usaha di bidang pupuk organik meliputi kegiatan pre-treatment vinasse dan pembiakan bioaktivator hingga menjadi produk siap pakai. Riset lain dilakukan oleh Adi Ratriyanto dkk. (2019) menghasilkan pupuk untuk meningkatkan produktivitas pertanian kelompok tani Karanganyar [5]. Pengabdian serupa dilakukan oleh Syaiful Arif (2020) yang bermitra dengan warga Dusun Genuk, Ponorogo. Riset tersebut juga menghasilkan pupuk agar dapat digunakan warga pemilik ternak untuk menekan biaya produksi pertanian [6]. Riset terakhir dilakukan oleh Eksa Rusdiyana dkk. (2020) mengenai 
partisipasi petani dalam pelatihan pembuatan pupuk organik [7]. Hasilnya, Poktan Sukamaju, Karanganyar memiliki modal sosial berupa semangat, kepercayaan kelompok, dan jaringan yang baik untuk mengembangkan pembuatan pupuk organik cair dan pupuk organik padat melalui program pelatihan yang telah dilaksanakan.

\section{METODE PELAKSANAAN}

Pelaksanaan program ini dibagi menjadi beberapa tahap antara lain:

\section{Tahap Sosialisasi}

Pada tahap ini dilakukan penyuluhan kepada masyarakat kelompok tani Gapoktan Desa Sambirembe sekaligus pembuatan petunjuk operasional berupa banner yang dipasang di kandang sapi tempat pembuatan pupuk. Penyuluhan dilakukan oleh pemateri dari Jatikuwung Innovation Center (JIC) dengan metode diskusi dan tanya jawab dengan masyarakat kelompok tani. Penyuluhan dilakukan agar masyarakat kelompok tani gapoktan memahami tahapan pembuatan pupuk organik selama kegiatan pengabdian berlangsung dan masyarakat mampu melakukan pembuatan pupuk secara mandiri berdasarkan materi yang telah diberikan dan petunjuk operasional yang telah dipasang di kandang.

\section{Tahap Pembuatan Pupuk}

Pada tahap ini dilakukan pembuatan pupuk dari kotoran sapi bersama masyarakat kelompok tani Gapoktan Desa Sambirembe dan monitoring selama kegiatan berlangsung. Pada pelatihan ini, akan dipraktikkan pembuatan pupuk organik kotoran sapi mulai dari persiapan sampai pengemasan Secara garis besar proses pembuatan pupuk organik kotoran sapi sebagai berikut.

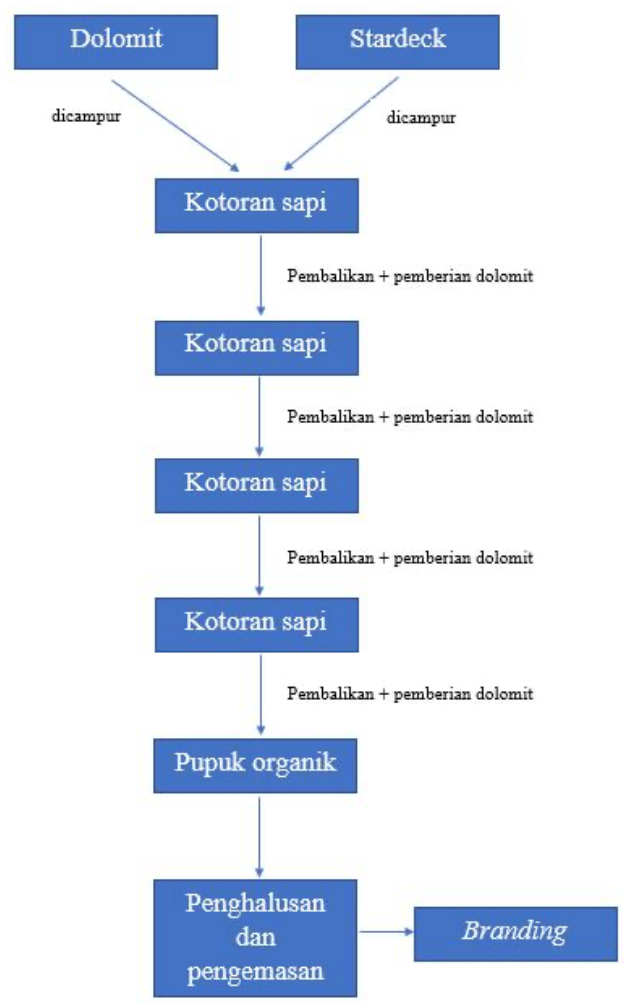

Gambar 3. Diagram alir pembuatan pupuk organik kotoran sapi 
Proses pembuatan pupuk dimulai dengan pencampuran dolomit dan stardeck dengan perbandingan 4:1. Penambahan dolomit pada proses pengomposan diperkirakan mampu mempercepat pengomposan, membuat kompos lebih stabil, lebih cepat matang (Moelyaningrum dkk., 2013) [8]. Stardek merupakan biostarter yang dalam pembuatan pupuk organik berperan sebagai pengurai yang mempercepat proses fermentasi (Sukmawati dkk., 2019) [9]. Campuran dolomit dan stardeck dicampur ke kotoran sapi setiap ketebalan $20 \mathrm{~cm}$ agar campuran dolomit dan stardeck tercampur merata dengan kotoran sapi. Proses selanjutnya kotoran sapi didiamkan selama seminggu agar kotoran sapi terfermentasi setelah itu ditambahkan dolomit pada kotoran sapi setiap ketebalan $20 \mathrm{~cm}$ hingga merata. Proses tersebut diulang seminggu sekali selama 4 minggu hingga pupuk siap digunakan. Pupuk yang telah siap digunakan tersebut dihaluskan menggunakan mesin grinder dan dikemas.

\section{Tahap Branding dan pemasaran}

Pada tahap ini, pupuk yang sudah jadi dan dikemas dibuat brand dengan tujuan agar pupuk tersebut dapat dikenal oleh masyarakat luas. Branding disosialisasikan ke kelompok pemuda karang taruna Desa Sambirembe dilakukan oleh mahasiswa KKN UNS dengan metode diskusi dan tanya jawab. Tahap ini sekaligus mensosialisasikan ke kelompok pemuda karang taruna Desa Sambirembe sasaran pemasaran pupuk berlabel "Pupuk Kandang Sambirembe" melalui berbagai platform seperti e-commerce, laman web, dan pemasaran secara konvensional di toko pertanian.

\section{HASIL}

\section{Tahap Sosialisasi}

Sosialisasi berupa pembuatan pupuk organik mendapat antusias yang baik dari masyarakat. Dalam sesi tanya jawab peserta secara menyeluruh ikut bertanya kepada pembicara tentang materi yang diberikan. Masyarakat mendapat gambaran kedepan tentang pengolahan kotoran ternak menjadi pupuk organik dengan mengikuti tata cara pembuatan yang telah disampaikan pada materi sosialisasi. Masyarakat juga terbantu dengan adanya poster yang dipasang pada dinding kandang sewaktu-waktu jika mereka lupa dengan tahapan pembuatannya. Masyarakat juga menjadi lebih paham tentang bahan dan alat apa yang digunakan dalam pembuatan pupuk organik serta juga memahami proporsi penggunaan bahannya

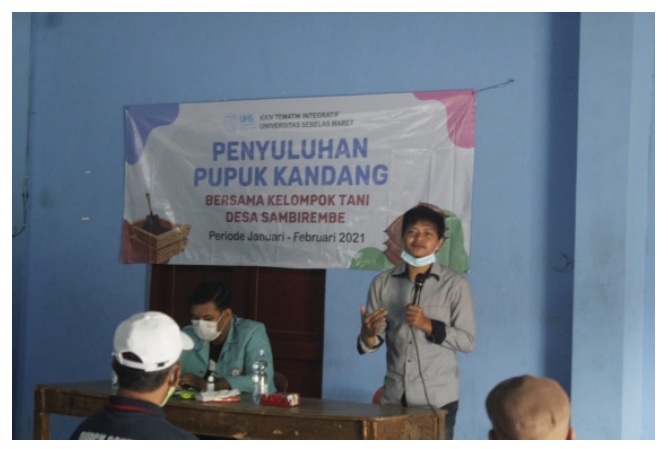

Gambar 4. Sosialisasi Penyuluhan Pupuk Kandang 


\section{Tahap Pembuatan Pupuk}

Tahapan pembuatan pupuk ditanggapi dengan sangat antusias oleh masyarakat dimana mereka ikut turun ke lapangan dalam setiap proses pembuatan pupuk. Masyarakat juga tidak segan-segan bertanya-tanya tentang cara terbaik dalam pembuatan pupuk organik agar mendapatkan hasil maksimal. Masyarakat juga turut memikirkan pembenahan-pembenahan yang perlu dilakukan di tempat produksi pupuk untuk keberlangsungan proses yang lebih baik. Masyarakat jadi dapat memanfaatkan kotoran sapi yang sebelumnya hanya ditumpuk menjadi bernilai lebih dengan adanya pembuatan pupuk organik.

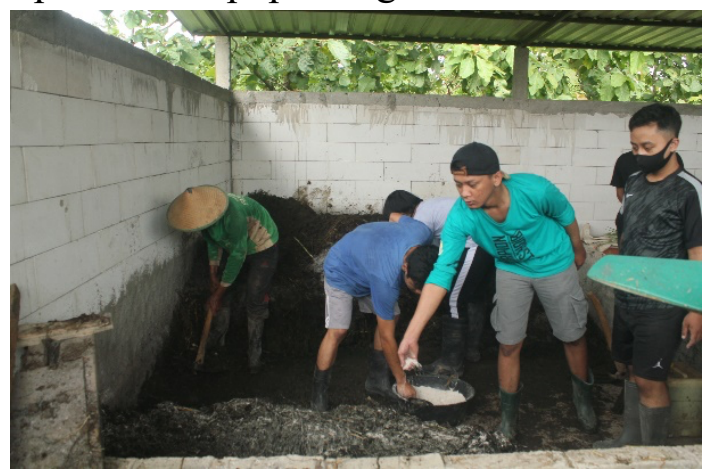

Gambar 5. Penaburan Stardeck dan Dolomit ke Limah Kotoran Sapi

\section{Tahap Branding dan pemasaran}

Masyarakat yang tergabung dalam gapoktan sambirembe merasa terbantu dengan adanya kegiatan branding dan pemasaran ini. masyarakat menjadi tersadar bahwa pupuk yang diproduksi sendiri dari kotoran ternak mempunyai peminat yang banyak di pasaran apabila dikemas dalam bentuk yang menarik. Masyarakat juga memahami bahwa produk pupuk yang mereka hasilkan tidak hanya dapat dipasarkan di toko-toko namun juga dapat ditawarkan secara daring dan menyadari bahwa di era digital dapat mempermudah pemasaran produk pupuk.

\section{KESIMPULAN}

Masyarakat Desa Sambirembe khususnya kelompok gapoktan sambirembe menjadi lebih paham tentang pemanfaatan kotoran ternak menjadi pupuk organik dengan proses yang tepat. Masyarakat desa memiliki brand produk pupuk organik sendiri untuk dapat dipasarkan baik secara daring maupun luring. Tahapan pembuatan pupuk ditanggapi dengan sangat antusias oleh masyarakat dimana mereka ikut turun ke lapangan dalam setiap proses pembuatan pupuk. Masyarakat yang tergabung dalam gapoktan sambirembe merasa terbantu dengan adanya kegiatan branding dan pemasaran ini. Masyarakat menjadi tersadar bahwa pupuk yang diproduksi sendiri dari kotoran ternak mempunyai peminat yang banyak di pasaran apabila dikemas dalam bentuk yang menarik. Masyarakat juga memahami bahwa produk pupuk yang mereka hasilkan Penghasilan dari pengolahan kotoran ternak menjadi pupuk organik dapat menjadi tambahan pemasukan bagi masyarakat bahkan ditengah pandemi.

\section{Ucapan Terima Kasih}

Terima kasih kami sampaikan kepada Lembaga Penelitian dan Pengabdian Masyarakat 
(LPPM) Universitas Sebelas Maret, Surakarta atas hibah pendanaan untuk program pengabdian masyarakat melalui kegiatan Kuliah Kerja Nyata periode Januari-Februari 2021. Selain itu, ucapan terima kasih disampaikan kepada Gabungan Kelompok Tani (Gapoktan) Desa Sambirembe, Kecamatan Kalijambe, Kabupaten Sragen sebagai mitra sekaligus kelompok sasaran dari program pengabdian masyarakat berupa pemanfaatan limbah kotoran sapi menjadi pupuk organik.

\section{DAFTAR PUSTAKA}

[1] Badan Pusat Statistik. Kecamatan Kalijambe dalam Angka. $<$ https://Sragenkab.bps.go.id $>$ Diunduh pada 03 Januari 2020, Pukul 09.37 WIB.

[2] Kementerian Pertanian Republik Indonesia. Peraturan Menteri Pertanian Republik Indonesia Nomor 67/Permentan/SM.050/12/2016 tentang Pembinaan Kelembagaan Petani. $\leq \mathrm{http}: / /$ perundangan.pertanian.go.id/admin/p mentan/Permentan\%20672016\%20Pembinaan\%20Kelembagaan\%20Petani.pdf> Diunduh pada 6 Februari 2021, Pukul 08:02 WIB.

[3] B. S. Setiawan,. Membuat Pupuk Kandang Secara Cepat, Depok, Penebar Swadaya. 2010.

[4] H Mulyani, I Ifandari, RB Nugroho. Perintisan Usaha Bersama di Bidang Produksi Pupuk Organik bagi Gabungan Kelompok Petani Tani Makmur dan UKM Industri Alkohol Ngombakan. Jurnal Semar, Vol. 5, No. 1, hlm 1-11. 2016.

[5] A Ratriyanto, SD Widyawati, Suprayogi, Wara P.S., S. Prastowo,., N. Widyas. Pembuatan Pupuk Organik dari Kotoran Ternak untuk Meningkatkan Produksi Pertanian. Jurnal Semar, Vol. 8, No. 1 hlm 9-13. 2019.

[6] S. Arif., Pembuatan Pupuk Organik Berbahan Limbah Kotoran Sapi untuk Meningkatkan Produktifitas Pertanian Warga di Dusun Genuk Desa Snepo Kec. Slahung Kab. Ponorogo, Indonesian Engagement Journal, Vol. 1, No. $2 \mathrm{hlm} 117-127.2020$

[7] E. Rusdiyana, M. Cahyadi, A. Pramono, A.W. Budiman. Partisipasi Petani dalam Pelatihan Pembuatan Pupuk Organik Berbasis Kotoran Sapi di Desa Kaliboto. Jurnal Qardhul Hasan: Media Pengabdian kepada Masyarakat, Vol. 6, No. 2, hlm 127-133. 2020.

[8] AD Moelyaningrum, E Ellyke, RS Pujiati. Penggunaan Dolomit ( $\mathrm{MgCa}(\mathrm{CO} 3) 2)$ Sebagai Penstabil PH Pada Kompositing Sampah Dapur Berbasis Dekomposisi Anaerob dan Aerob, Jurnal IKSEMA, Vol. 9, No. 2, 74-82. 2013.

[9] NMS Sukmawati, NW Suniti, IN Sujana. Aplikasi Teknologi Fermentasi Dalam Pembuatan Biostarter Berbasis Daun dan Buah di Desa Antapan Baturiti Tabanan, Buletin Udayana Mengabdi, Vol. 18, No. 1, 138-142. 2019. 